\title{
DETECTION AND MOLECULAR EPIDEMIOLOGY OF HUMAN \\ BOCAVIRUS IN CHILDREN WITH ACUTE GASTROENTERITIS FROM \\ BRAZIL
}

L.S. SOARES ${ }^{1 *}$, A. B. LIMA ${ }^{1}$, K.C. PANTOJA ${ }^{1}$, P.S. LOBO ${ }^{1}$, J.F. CRUZ1 ${ }^{1}$, S.F.S.

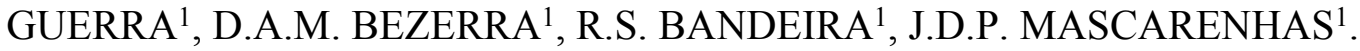

${ }^{1}$ Secretaria de Vigilância em Saúde, Instituto Evandro Chagas, Seção de Virologia, Ananindeua, PA, Brasil

*Author for correspondence: Luana da Silva Soares, Seção de Virologia, Instituto Evandro Chagas, Secretaria de Vigilância em Saúde, Ministério da Saúde, Rodovia BR 316-KM 07, S/N, Levilândia, 67.030-000, Ananindeua, Pará, Brazil.

Tel: + 5591 32142020; Fax + 559132142006 .

E-mail: luanasoares@iec.pa.gov.br.

Running title: Molecular Epidemiology of $\mathrm{HBoV}$ in Brazil. 


\section{SUMMARY}

Human Bocavirus $(\mathrm{HBoV})$ is a recently discovered virus and was first detected in the nasopharyngeal aspirate samples and after in stool samples, suggesting that HBoV may be a causative agent for human enteric infections. Due to absence of treatment options, there is a need to understand the disease-causing mechanism of these viruses. The aim of this was to demonstrate the prevalence of $\mathrm{HBoV}$ from children less than 10 years with acute gastroenteritis in Brazil, during November 2011 to November 2012. Stool samples from hospitalized children $\leq 10$ years who presented symptoms of acute gastroenteritis were analyzed for the presence of HBoV DNA by nested-PCR. HBoVpositivity was detected in $24.0 \%(54 / 225)$ of samples. Two peaks of $\mathrm{HBoV}$ detection were observed, during November 2011 and July to September 2012. Co-infections between $\mathrm{HBoV}$ and rotavirus $\mathrm{A}$ were identified in $50.0 \%(27 / 54)$ of specimens. Phylogenetic analysis identified the presence of HBoV-1 (94.8\%), HBoV-2 (2.6\%) and HBoV-3 (2.6\%) species, with only minor variations among them. Further investigations are necessary to improve the knowledge on the role of $\mathrm{HBoV}$ in gastrointestinal infections.

Key words: Human bocavirus, children, acute gastroenteritis. 


\section{INTRODUCTION}

Globally, diarrhoeal disease in 2015 were responsible for 499000 deaths of children aged $<5$ years (1). Several pathogens are associated with acute gastroenteritis (AGE), however $\sim 40 \%$ of cases remain of unknown etiology (2). Human Bocavirus $(\mathrm{HBoV})$ is a recently discovered virus and was first detected in the nasopharyngeal aspirate samples and after in stool samples, suggesting that $\mathrm{HBoV}$ may be a causative agent for human enteric infections (3-5).

$\mathrm{HBoV}$ belongs to Parvoviridae family, Parvovirinae subfamily, Bocaparvovirus genus (6). This parvovirus is a small single stranded DNA virus with a diameter of 18-26 nanometers and contains a non-enveloped icosahedral capsid (7). The genome of $\mathrm{HBoV}$ consists of three ORFs that encode two non structural proteins (NS1 and NP1) and two structural proteins (VP1 and VP2) $(7,8)$. Based on genetic variability of VP1 region, $\mathrm{HBoV}$ are divided into 4 species: HBoV1 - HBoV4. Several groups have detected HBoV1 in respiratory tract infections, while $\mathrm{HBoV} 2,3$ and 4 were reported in fecal samples $(9,10)$.

The role of $\mathrm{HBoV}$ in respiratory disease and acute gastroenteritis remains unclear. It is believed that $\mathrm{HBoV}$ can persist for a longer period in respiratory tract mucosa, reaches the bloodstream or ingestion and migrates to gastrointestinal tract, where it may generate a new infection or be excreted in an asymptomatic way (11). However, there are increasing reports on $\mathrm{HBoV}$ detection in fecal specimens from patients with acute diarrhoea, particularly in children (12-14).

$\mathrm{HBoV}$ have been detected mostly in respiratory tract secretions and stool, however the viruses have been found in serum and cerebrospinal fluid causing viremia $(15,16)$. Likewise, several studies have reported $\mathrm{HBoV}$ in sewage and river water (1719). 
Since the first $\mathrm{HBoV}$ detection, several studies reported its association with respiratory and gastrointestinal infections, mostly in young children (12,20,21). Nevertheless, the significance of this virus as a causative agent in human infections remains unknown, due to high prevalence of co-infection with other viruses in symptomatic patients as well as to frequent detection of $\mathrm{HBoV}$ in asymptomatic individuals. A recent systematic review suggests that even though $\mathrm{HBoVs}$ are often considered bystanders in acute gastroenteritis course, HBoV-2 infection may increase the risk for this disease $(5,10,22)$.

Several studies have reported $\mathrm{HBoV}$ associated with respiratory and gastrointestinal tract infections as single pathogens, causing severe disease (21-23). Due to absence of treatment options, there is a need to understand the disease-causing mechanism of these viruses.

(10) have reported that $\mathrm{HBoV}$ prevalence was similar between subjects with or not gastrointestinal symptoms. HBoV has also been found to co-infect humans with other enteric viruses. A study conducted in Pakistan has related a frequency of $98 \%$ involved co-infection between $\mathrm{HBoV}$ and rotavirus from children with AGE (24). In Brazil in an investigation that also enrolled diarrheic children have described HBoV coinfection with norovirus, adenovirus and rotavirus in $19 \%, 3 \%$ and $3 \%$ of patients, respectively (12).

The aim of this was to demonstrate the prevalence of $\mathrm{HBoV}$ from children less than 10 years with AGE in Brazil, from November 2011 to November 2012, to report co-infection with rotavirus A (RVA) and to describe $\mathrm{HBoV}$ species.

\section{METHODS}

\section{Ethics Statement}


This study was approved by Evandro Chagas Institute's Human Research Ethics Committee, protocol number 414.389, in accordance with National Health Council's Resolution 466/2012. The authors ensure that all procedures contributing to this work comply with the ethical standards of the relevant national and institutional committees on human experimentation and with the Helsinki Declaration of 1975, as revised in 2008.

\section{Clinical Specimens}

Samples from this study were collected from hospitalized children $\leq 10$ years who presented symptoms of AGE and were selected from four states in Northern region of Brazil. During November 2011 to November 2012 a total of 541 fecal samples was collected and an aliquot of each sample was stored at $-20^{\circ} \mathrm{C}$ and transported to Evandro Chagas Institute, a Brazilian Ministry of Health's National Rotavirus Reference Laboratory. Acute diarrhoea was defined as the presence of three or more liquid and semi-liquid stools in a 24-hr period for up to 14 days. For the present study, it was selected 225 samples for $\mathrm{HBoV}$ testing, considering a 95\% confidence level and a sampling error of $5 \%$.

\section{Detection of RVA}

Fecal samples were screened for the presence of RVA by a commercially available enzyme-linked immunosorbent (ELISA) assay according to the manufacturer's instructions (Ridascreen kit, R-Biopharm ${ }^{\circledR}$, Darmstadt, Germany). 


\section{HBoV Screening and DNA Extraction}

Viral genome was extracted from 10\% fecal suspensions using guanidinium isothiocyanate-silica method (25). Posteriorly, samples were subjected to nested-PCR targeting the partial region of VP1 gene. The first-round of the nested-PCR was carried out using the AK-VP-F1 and AK-VP-R1 primers set, and the second round using the AK-VP-F2 and AK-VP-R2, as described previously (26).

\section{Nucleotide Sequencing and Phylogenetic Analysis}

Sequencing of the PCR amplicons $\mathrm{HBoV}$ strains were performed using the same primers as those used in the second-round of the nested-PCR and carried out with a Big Dye Terminator cycle sequencing kit v 3.1 (Applied Biosystems, Foster City, CA). Electrophoresis was performed on the ABI Prism 3130xl automatic sequencer (Applied Biosystems) and the sequences obtained were aligned and edited using the BioEdit Sequence Alignment Editor program (v. 7.0.5.2). Neighbor-joining method was used to perform the phylogenetic analysis, in which distance was calculated from aligned sequences (27). Dendrograms were constructed using MEGA program v.5.0.1, and bootstrap analysis was performed using 2,000 replicas. Partial nucleotide sequences from this study were deposited in the GenBank database (http://www.ncbi.nlm.nih.gov), under the following access number: MH003642-MH003679.

\section{Statistical Analysis}

$\mathrm{HBoV}$ frequencies and genotypes description were calculated using Microsoft Excel software. Comparisons of $\mathrm{HBoV}$ infection rates in distinct groups were performed using chi-square test $\left(\chi^{2}\right)$ through BioEstat 5.0 with statistical significance established of $\mathrm{P}$ values $<0.05$ (28). 


\section{RESULTS}

From November 2011 to November 2012 an overall HBoV-positivity was detected in $24.0 \%(54 / 225$, range $0-50 \%)$ of hospitalized children $\leq 10$ years using Nested-PCR. Figure 1 show the monthly frequencies of $\mathrm{HBoV}$ detection, with two peaks, where HBoV rates were over 30\%, November 2011 and July to September 2012. Samples were tested for RVA which is the most important viral agent associated with acute gastroenteritis. RVA detection was 40.9\% (92/225) and it was observed coinfection between $\mathrm{HBoV}$ and RVA in 50.0\% (27/54) of samples with median age of 17 months (data not shown).

General characteristics of HBoV-positive cases are summarized in Table I. The median age of children with $\mathrm{HBoV}$ was 16 months, with higher $\mathrm{HBoV}$ positivity $(66.6 \%, 36 / 54)$ was observed among children aged 7-24 months. With respect to gender, 59.2\% (32/54) of infected children were male. No statistically significant differences $(\mathrm{P}>0.5)$ were seen when comparing age groups and genders.

Phylogenetic analysis of partial region of VP1 genes were performed in 38 (70.3\%) HBoV positive samples, showing that HBoV1 were identified in $94.8 \%$ of samples $(n=36)$, while one isolate each belonged to HBoV-2 and HBoV-3 genotypes, respectively. All HBoV1 strains shared $97-100 \%$ and $93.1-100 \%$ nucleotide (nt) and amino acid (aa) similarities among themselves, respectively. When compared with another isolates $\mathrm{nt}$ and aa similarities ranged from $95.8-100 \%$ and $93.2-100 \%$, respectively. With regards $\mathrm{HBoV} 2$ and $\mathrm{HBoV} 3$ strains showed nt similarities ranged from $93.3-98.6 \%$ and $97.1-98.2 \%$ with prototype strains, respectively (Figure 2). 


\section{DISCUSSION}

This study reports $\mathrm{HBoV}$ detection among pediatric patients with acute gastroenteritis from Brazil, is demonstrated the prevalence of $\mathrm{HBoV}$ and describe its dominant species. $\mathrm{HBoV}$ was detected in $24.0 \%$ of patients. Presents findings were higher than most of the previously reported in Brazil, including a survey with HIVseropositive children hospitalized with acute diarrhoea, in which HBoV overall positivity rate was $14 \%(4,29-31)$.

$\mathrm{HBoV}$ and RVA co-infection is usually related. In the current study, this condition was observed in $50 \%$ of samples tested, a number comparable to the obtained for $\mathrm{HBoV}$ and diverse gastroenteritis viruses in an investigation performed in West China, between 2012 and 2013, in which the overall rate of co-detection was equivalent to $43,3 \%$ (23). In Pakistani children, $98 \%$ of $\mathrm{HBoV}$-positive samples also tested positive to RVA, a higher number than observed in the present results. It is important to notice that RVA vaccine is not included in vaccination program in Pakistan, and this may be an important contributing factor to the high prevalence of RVA among infants from that population (24). On the other hand, in Brazil, where the immunization program includes RVA vaccine, $\mathrm{HBoV}$ and RVA association was also found, but the major co-infection rate was noted between $\mathrm{HBoV}$ and noroviruses (12).

As the co-infection data were limited to RVA in the present investigation, since it was the only viral agent tested other than $\mathrm{HBoV}$, it was not possible to determine the relation of $\mathrm{HBoV}$ with other acute gastroenteritis causative virus. Another limitation consists in the absence of enough clinical data regarding to $\mathrm{HBoV}$ mono- and co-infections. Hence, it was not possible to stablish if there were significant differences in disease severity between these groups. 
Despite $\mathrm{HBoV}-2,-3$ and -4 are most associated with AGE symptoms while HBoV-1 is most related to respiratory tract diseases (Padhye et al., 2016), we identified a higher presence of $\mathrm{HBoV}-1$ among $\mathrm{HBoV}$-positive stool samples compared to the remaining species. Similar results were observed in Chile, where HBoV-1 was found in $14,1 \%$ of the HBoV-positive fecal specimens, between 1985 to 2010, and in other countries such as India, Thailand, Pakistan, South Korea and Australia (14,24,32-35).

An investigation performed at the same period (year of 2012) in Bahia state, Northeast Brazil, revealed, however, that $70 \%$ of $\mathrm{HBoV}$-positive sequenced samples were correspondent to specie 2 (subtype $2 \mathrm{~A}$ ), while only $30 \%$ were related to $\mathrm{HBoV}-1$ (12). In Southeast Brazil, a preview study has shown that $20.8 \%$ of a diarrheic group was characterized as $\mathrm{HBoV}-2$, whereas $1.2 \%$ corresponded to $\mathrm{HBoV}-1$ (29).

There is a current lack of data regarding to $\mathrm{HBoV}$ infection in Northern region of Brazil. Thus, it is difficult to compare the obtained results with other investigations about $\mathrm{HBoV}$ in this population and, likewise, to stablish the aspects of $\mathrm{HBoV}$ infection in this region. Therefore, based on the different species profile observed between distinct Brazilian regions, it is necessary to understand which peculiar characteristics from each location stimulate the propagation of diverse types of $\mathrm{HBoV}$ in several time spaces. Some factors as climate changes, economy and immunological situation of individuals are thought to be probable determinants of the observed particularities (36).

According to (37) the prevalence of $\mathrm{HBoV}$ species may fluctuate over the years, however, it was not possible to determine if the higher detection rate of $\mathrm{HBoV}-1$ in Brazil was due to this factor, as only one year was evaluated on the present investigation. 
Further investigations are necessary to improve the knowledge on the role of $\mathrm{HBoV}$ in gastrointestinal infections. Once $\mathrm{HBoV}$ was found with and without association to RVA, new data are important to understand the possible role of this virus in acute gastroenteritis.

\section{ACKNOWLEDGEMENTS}

The authors would like to acknowledge the staff of State Central Laboratories (LACENs) and the technical assistance given by the laboratory personnel at the Seção de Virologia of the Instituto Evandro Chagas. The authors are also thankful to the children/mothers who agreed to participate in this study as volunteers and permitted the analysis of their relevant biological material.

\section{AUTHOR'S CONTRIBUTION}

ABFL, KCP, JFC: performed the experiments. PSL, SFSG, DAMB, RSB: carried out molecular and the phylogenetic analyses. LSS, ABFL: analysed, interpreted data and drafted the manuscript. LSS, JDPM: provided critical review of manuscript. All authors read and approved the final manuscript.

\section{FINANCIAL SUPPORT}

This research received no specific grant from any funding agency, commercial or not-for-profit sectors.

\section{CONFLICT OF INTEREST}

None. 


\section{REFERENCES}

1. GBD Diarrhoeal Diseases Collaborators. Estimates of global, regional, and national morbidity, mortality, and aetiologies of diarrhoeal diseases: a systematic analysis for the Global Burden of Disease Study 2015. Lancet Infect Dis. 2017;17(9):909-48.

2. Nicholson MR, Van Horn GT, Tang Y-W, Vinjé J, Payne DC, Edwards KM, et al. Using Multiplex Molecular Testing to Determine the Etiology of Acute Gastroenteritis in Children. J Pediatr. 2016;176:50-56.e2.

3. Allander T, Tammi MT, Eriksson M, Bjerkner A, Tiveljung-Lindell A, Andersson B. Cloning of a human parvovirus by molecular screening of respiratory tract samples. Proc Natl Acad Sci U S A. 2005;102(36):12891-6.

4. Albuquerque MCM, Rocha LN, Benati FJ, Soares CC, Maranhão AG, Ramírez ML, et al. Human bocavirus infection in children with gastroenteritis, Brazil. Emerg Infect Dis. 2007;13(11):1756-8.

5. Guido M, Tumolo MR, Verri T, Romano A, Serio F, De Giorgi M, et al. Human bocavirus: Current knowledge and future challenges. World J Gastroenterol. 2016;22(39):8684-97.

6. International Committee on Taxonomy of Viruses (ICTV) [Internet]. [cited Feb 2018]. https://talk.ictvonline.org/taxonomy/

7. Gurda BL, Parent KN, Bladek H, Sinkovits RS, DiMattia MA, Rence C, et al. Human bocavirus capsid structure: insights into the structural repertoire of the parvoviridae. J Virol. 2010;84(12):5880-9.

8. Cashman O, O'Shea H. Detection of human bocaviruses 1,2 and 3 in Irish children presenting with gastroenteritis. Arch Virol. 2012;157(9):1767-73.

9. Jartti T, Hedman K, Jartti L, Ruuskanen O, Allander T, Söderlund-Venermo M. Human bocavirus-the first 5 years. Rev Med Virol. 2012;22(1):46-64.

10. Ong DSY, Schuurman R, Heikens E. Human bocavirus in stool: A true pathogen or an innocent bystander? J Clin Virol Off Publ Pan Am Soc Clin Virol. 2016;74:45-9.

11. Schildgen O. Human bocavirus: lessons learned to date. Pathog Basel Switz. 2013;2(1):1-12.

12. Campos GS, Silva Sampaio ML, Menezes ADL, Tigre DM, Moura Costa LF, Chinalia FA, et al. Human bocavirus in acute gastroenteritis in children in Brazil. J Med Virol. 2016;88(1):166-70.

13. La Rosa G, Della Libera S, Iaconelli M, Donia D, Cenko F, Xhelilaj G, et al. Human bocavirus in children with acute gastroenteritis in Albania. J Med Virol. 2016;88(5):906-10. 
14. Lasure N, Gopalkrishna V. Molecular epidemiology and clinical severity of Human Bocavirus (HBoV) 1-4 in children with acute gastroenteritis from Pune, Western India. J Med Virol. 2017;89(1):17-23.

15. Tozer SJ, Lambert SB, Whiley DM, Bialasiewicz S, Lyon MJ, Nissen MD, et al. Detection of human bocavirus in respiratory, fecal, and blood samples by real-time PCR. J Med Virol. 2009;81(3):488-93.

16. Bubshait DK, Albuali WH, Yousef AA, Obeid OE, Alkharsah KR, Hassan MI, et al. Clinical description of human bocavirus viremia in children with LRTI, Eastern Province, Saudi Arabia. Ann Thorac Med. 2015;10(2):146-9.

17. Hamza IA, Jurzik L, Wilhelm M, Uberla K. Detection and quantification of human bocavirus in river water. J Gen Virol. 2009;90(Pt 11):2634-7.

18. Myrmel M, Lange H, Rimstad E. A 1-Year Quantitative Survey of Noro-, Adeno-, Human Boca-, and Hepatitis E Viruses in Raw and Secondarily Treated Sewage from Two Plants in Norway. Food Environ Virol. 2015;7(3):213-23.

19. Iaconelli M, Divizia M, Della Libera S, Di Bonito P, La Rosa G. Frequent Detection and Genetic Diversity of Human Bocavirus in Urban Sewage Samples. Food Environ Virol. 2016;8(4):289-95.

20. Moesker FM, Kampen JJA van, Eijk AA van der, Rossum AMC van, Hoog M de, Schutten M, et al. Human bocavirus infection as a cause of severe acute respiratory tract infection in children. Clin Microbiol Infect. 2015;21(10):964.e1-964.e8.

21. Broccolo F, Falcone V, Esposito S, Toniolo A. Human bocaviruses: Possible etiologic role in respiratory infection. J Clin Virol Off Publ Pan Am Soc Clin Virol. 2015;72:75-81.

22. De R, Liu L, Qian Y, Zhu R, Deng J, Wang F, et al. Risk of acute gastroenteritis associated with human bocavirus infection in children: A systematic review and meta-analysis. PloS One. 2017;12(9):e0184833.

23. Zhou T, Chen Y, Chen J, Hu P, Zheng T, Xu X, et al. Prevalence and clinical profile of human bocavirus in children with acute gastroenteritis in Chengdu, West China, 2012-2013. J Med Virol. 2017;89(10):1743-8.

24. Alam MM, Khurshid A, Shaukat S, Sharif S, Suleman RM, Angez M, et al. Human bocavirus in Pakistani children with gastroenteritis. J Med Virol. 2015;87(4):656-63.

25. Boom R, Sol CJ, Salimans MM, Jansen CL, Wertheim-van Dillen PM, van der Noordaa J. Rapid and simple method for purification of nucleic acids. J Clin Microbiol. 1990;28(3):495-503.

26. Kapoor A, Simmonds P, Slikas E, Li L, Bodhidatta L, Sethabutr O, et al. Human bocaviruses are highly diverse, dispersed, recombination prone, and prevalent in enteric infections. J Infect Dis. 2010;201(11):1633-43. 
27. Kimura M. A simple method for estimating evolutionary rates of base substitutions through comparative studies of nucleotide sequences. J Mol Evol. 1980;16(2):11120 .

28. Ayres, M., Ayres Jr, M., Ayres, D., Santos, A. BIOESTAT -Aplicações estatísticas nas áreas das ciências bio-médicas. $5^{\circ}$ ed. Belém,PA: Ong Mamiraua; 2007.

29. Santos N, Peret TCT, Humphrey CD, Albuquerque MCM, Silva RC, Benati FJ, et al. Human bocavirus species 2 and 3 in Brazil. J Clin Virol Off Publ Pan Am Soc Clin Virol. 2010; 48(2):127-30.

30. Sousa TT de, Souza M, Fiaccadori FS, Borges AMT, Costa PS da, Cardoso D das $\mathrm{D}$ de $\mathrm{P}$. Human bocavirus 1 and 3 infection in children with acute gastroenteritis in Brazil. Mem Inst Oswaldo Cruz. 2012;107(6):800-4.

31. Portes SAR, Carvalho-Costa FA, Rocha MS, Fumian TM, Maranhão AG, de Assis RM, et al. Enteric viruses in HIV-1 seropositive and HIV-1 seronegative children with diarrheal diseases in Brazil. PloS One. 2017;12(8):e0183196.

32. Han T-H, Kim C-H, Park S-H, Kim E-J, Chung J-Y, Hwang E-S. Detection of human bocavirus-2 in children with acute gastroenteritis in South Korea. Arch Virol. 2009;154(12):1923-7.

33. Arthur JL, Higgins GD, Davidson GP, Givney RC, Ratcliff RM. A novel bocavirus associated with acute gastroenteritis in Australian children. PLoS Pathog. 2009;5(4):e1000391.

34. Khamrin P, Thongprachum A, Shimizu H, Okitsu S, Mizuguchi M, Hayakawa S, et al. Detection of human bocavirus 1 and 2 from children with acute gastroenteritis in Japan. J Med Virol. 2012;84(6):901-5.

35. Levican J, Navas E, Orizola J, Avendaño LF, Gaggero A. Human bocavirus in children with acute gastroenteritis, Chile, 1985-2010. Emerg Infect Dis. 2013;19(11):1877-80.

36. Schildgen O, Müller A, Simon A. Human bocavirus and gastroenteritis. Emerg Infect Dis. 2007;13(10):1620-1.

37. Tymentsev A, Tikunov A, Zhirakovskaia E, Kurilschikov A, Babkin I, Klemesheva V, et al. Human bocavirus in hospitalized children with acute gastroenteritis in Russia from 2010 to 2012. Infect Genet Evol J Mol Epidemiol Evol Genet Infect Dis. 2016;37:143-9. 
Table I. Baseline Characteristics of HBoV-Positive Cases in

Brazil, 2011-2012.

HBoV positive/

tested $(\%)$

Age group (months)

$0-6$

$11 / 50(22.0)$

$7-24$

$36 / 126(28.6)$

$25-60$

$6 / 45(14.2)$

$>61$

$1 / 4(25.0)$

Clinical characteristics

Fever

24/110 (21.8)

Vomiting

28/141 (17.0)

Gender

Male

32/134 (23.8)

Female

$22 / 91 \quad(24.1)$

Brazilian State

Acre

13/47 (27.6)

Amazonas

38/133 (28.5)

Pará

$2 / 40 \quad(5.0)$

Roraima

$1 / 5 \quad(20.0)$ 
Figure 1. Temporal distribution of HBoV in Brazil, 2011-2012.

Figure 2. Phylogenetic analysis of VP1 protein of HBoV Brazilian strains. The level of bootstrap support is indicated at each node (values $<70 \%$ were omitted) based on neighbor-joining analysis of 2000 replications. HBoV strains analyzed in this study are in bold and with circle $(\bullet)$. 


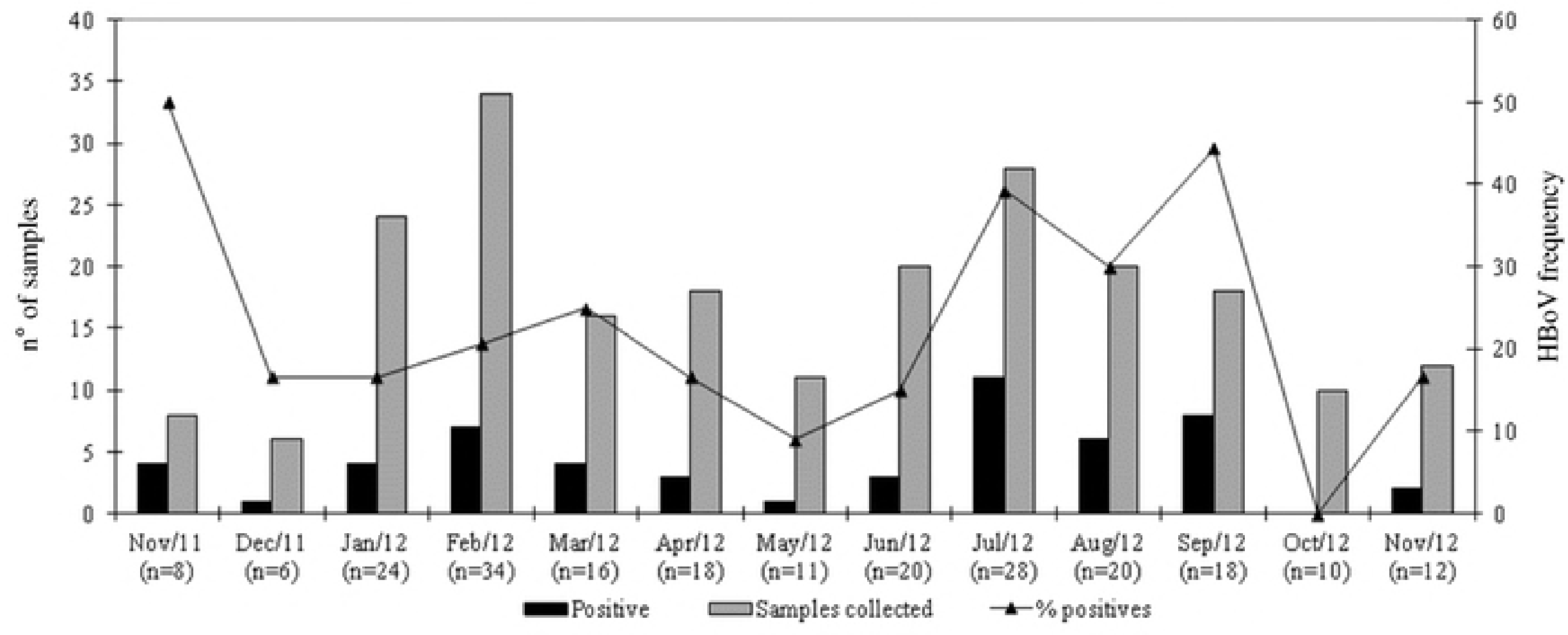




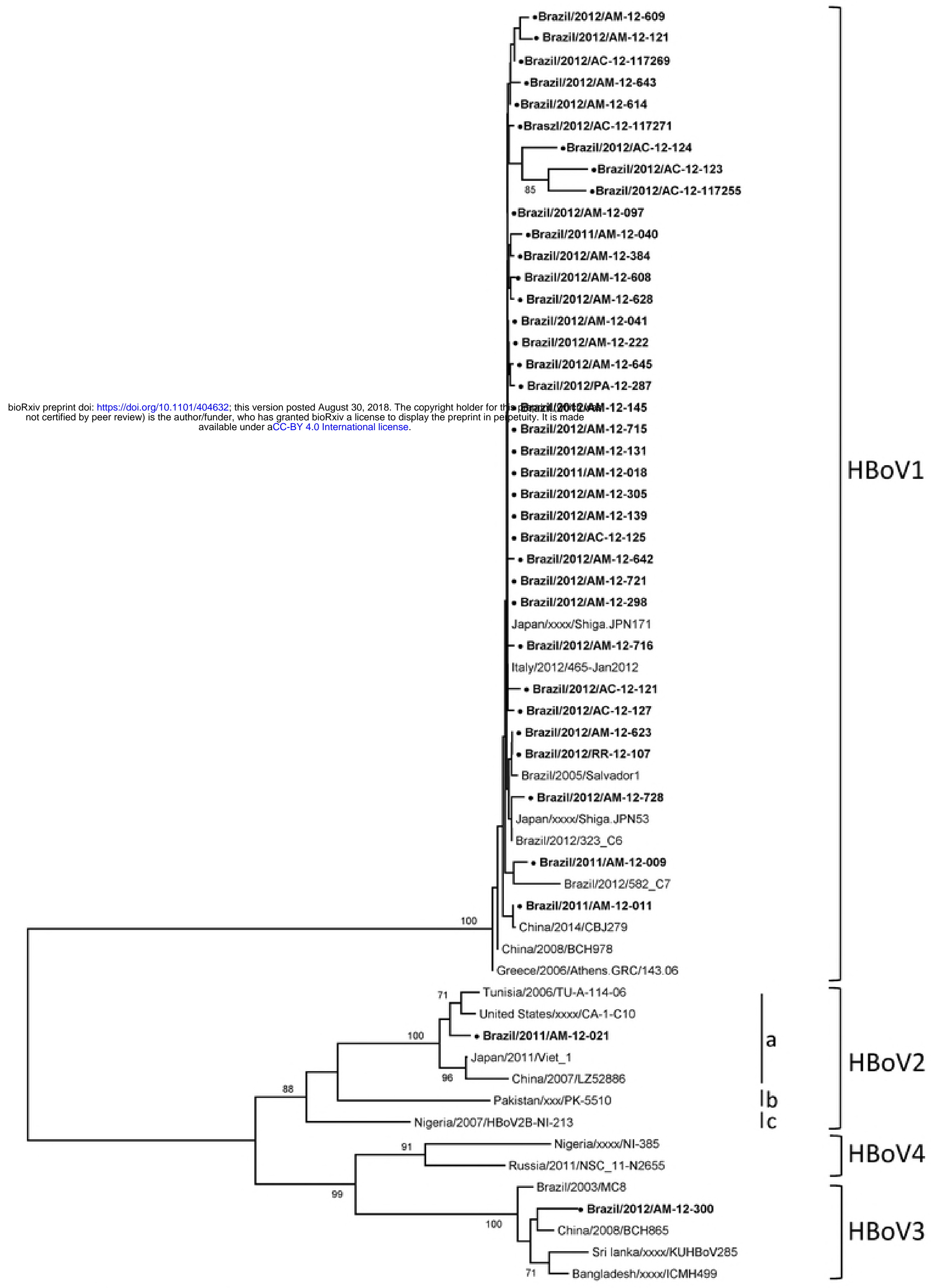

